\title{
O ECONÔMICO NA GEOGRAFIA: UMA REFLEXÃOA PARTIR DA PRODUÇÃO GEOGRÁFICA DA USP ${ }^{1}$ \\ The economical in the Geography: a reflection starting from the USP'S geographical production
}

\author{
Flaviana Gasparotti NUNES²
}

\section{RESUMO:}

Este artigo tem por objetivo apontar algumas questões e elementos para a reflexão acerca da presença e do papel do econômico na análise geográfica. A discussão teve por base a análise das teses de doutorado defendidas na FFLCH/USP no período de 1970-2001, cujas temáticas e formas de abordagem foram identificadas no âmbito da Geografia Econômica. A partir desta análise foram identificadas as principais influências relativas aos referenciais econômicos, podendo-se afirmar que a introdução do materialismo histórico a partir de teorias, conceitos, idéias e proposições metodológicas foi o principal caminho de afirmação do econômico na análise geográfica, visto que a partir desta base teórico-metodológica o econômico ganha importância, tendo papel central nas análises.

\section{Palavras-chave:}

Pensamento geográfico, USP, geografia econômica, epistemologia.

\begin{abstract}
:
This article aims at pointing at some subjects and elements for the reflection concerning the presence and role of the economical in the geographical analysis. The discussion had for base the analysis of the doctorate thesis presented at FFLCH/USP in the period of 1970-2001 whose themes and approach forms were identified in the extent of the Economic Geography. Starting from this analysis, they were identified by the main influences relative to the economical references and we could say that introducing historical materialism through theories, concepts, ideas and methodological statements has been the main way of highlighting the economic element in geographic analysis, since the theoretical-methodological basis employed in this work allows for a strengthening of the economic element, which takes the central role in the analyses.
\end{abstract}

Key-words:

Geographic thought, USP, economic geography, epistemology.

\footnotetext{
${ }^{1}$ Este artigo apresenta parte das reflexões desenvolvidas em nossa tese de doutorado intitulada: O econômico na geografia: influências do pensamento econômico na produção geográfica (1970-2001), defendida em outubro de 2004 junto ao Programa de Pós-Graduação em Geografia da Unesp - Campus de Presidente Prudente, sob orientação do Prof. Dr. Eliseu Savério Sposito.

${ }_{2}^{2}$ Profa. Adjunta do Curso de Geografia da Universidade Estadual do Oeste do Paraná (Unioeste) - Campus de Marechal Cândido Rondon - Doutora em Geografia pela FCT/Unesp/Pres. Prudente. E-mail: flaviana.nunes@ig.com.br
} 
NUNES, F. G. O econômico na geografia: uma reflexão a partir da produção...

\section{INTRODUÇÃO}

Este trabalho tem por objetivo apontar algumas questões e elementos para a reflexão acerca da presença e do papel do econômico na análise geográfica. As idéias aqui apresentadas têm por base uma pesquisa maior que desenvolvemos sobre as influências dos referenciais econômicos presentes na produção geográfica nacional.

Acreditamos ser este um tema relevante enquanto contribuição para a historiografia geográfica brasileira, tendo em vista o fato de que são poucos os trabalhos até então elaborados dedicados à reflexão sobre a produção geográfica brasileira no sentido de uma sistematização de suas principais características, elementos e questões. ${ }^{3}$

$\mathrm{O}$ aspecto priorizado diz respeito ao elemento econômico e sua presença nos estudos geográficos, ou seja, o foco das análises e reflexões realizadas recaiu sobre os trabalhos de geografia em que o econômico comparece como elemento essencial e central. Poderíamos dizer que se trata de trabalhos de Geografia Econômica, entendida aqui como campo da Geografia que se sustenta primeiramente por apresentar uma característica básica: a precedência do fato/evento econômico na determinação dos processos e relações que produzem as diferentes formas espaciais.

De um modo geral, poderíamos dizer que o enfoque econômico na abordagem geográfica relacionase à espacialidade dos fatos econômicos, visto que esses fatos têm a capacidade de se expressar e de se materializar no espaço.

Sendo assim, do ponto de vista da metodologia empregada, esta reflexão teve por base a análise das teses de doutorado defendidas na FFLCH/USP no período de 1970-2001, cujas temáticas e formas de abordagem foram identificadas no âmbito da Geografia Econômica.

A opção pelas teses defendidas na FFLCH/USP justifica-se pelo fato de que o Programa de Pósgraduação em Geografia Humana desta faculdade possui uma expressão nacional, pois durante muitos anos constituiu-se e ainda se constitui como um referencial da produção geográfica brasileira em âmbito científico acadêmico, conforme destaca Carlos (2002, p. 163-164):

Do ponto de vista da história da produção geográfica brasileira, há dois grandes centros - São Paulo e Rio de Janeiro - que dominam a formação de pesquisadores bem como a produção intelectual da geografia brasileira. Fato este que ocorre até o presente, quando começam a surgir outros cursos de pós-graduação no país (que em boa hora, são criados para atenuar as disparidades regionais). Um dado desta concentração é o fato de em 2001, o Departamento de Geografia da USP ter produzido $60 \%$ das teses de doutorado de todo o Brasil e mais de $25 \%$ dos mestrados.

Além disso, entendemos que as teses de doutorado expressam reflexões mais aprofundadas no que diz respeito à produção científica acadêmica.

Devemos lembrar que inicialmente a seleção das teses teve por base o objeto de que tratam. Neste momento, a pesquisa se baseou na identificação de fenômenos e de situações de natureza econômica relacionados ao espaço. Posteriormente, verificamos qual o recorte utilizado para tratar de tal temática. $O$ recorte é a via pela qual o objeto foi identificado e estudado pelo autor.

$\mathrm{Na}$ seqüência do texto, procuraremos mostrar alguns elementos e questões levantadas a partir dessa análise.

\section{A PRESENÇA DO ECONÔMICO NO PENSAMENTO GEOGRÁFICO: UMA INTERPRETAÇÃO POSSÍVEL}

Antes de abordarmos efetivamente a análise das teses, entendemos ser relevante resgatar as matrizes constitutivas do pensamento geográfico brasileiro, procurando entender como o econômico foi trabalhado ao longo desta trajetória, para que possamos estabelecer as possíveis relações com os próprios trabalhos analisados.

Para isso, adotamos o ponto de vista estabelecido por Oliveira (1999) que, por sua vez, ampara-se principalmente nas discussões de Capel (1981), por entendermos que a reflexão sobre o pensamento geográfico deve estar diretamente relacionada ao debate científico hegemônico estabelecido no período. Acreditamos que, ao resgatar o debate científico do período, podemos entender melhor as correntes filosóficas produzidas em cada contexto.

Sendo assim, a reflexão sobre o pensamento geográfico pautou-se na discussão das três principais correntes filosóficas que influenciaram diretamente na constituição e no desenvolvimento deste pensamento: positivismo, historicismo e dialética. Para Löwy (1985,

${ }^{3}$ Podemos lembrar neste caso o trabalho de Ferreira, Darlene Ap. de O. Mundo rural e Geografia: Geografia Agrária no Brasil (19301990). São Paulo: Unesp, 2002. 
NUNES, F. G. O econômico na geografia: uma reflexão a partir da produção...

p. 35), estas três proposições teórico-metodológicas estabelecem relações de leitura tanto entre os valores e a ciência, quanto entre esta e as ideologias.

Tendo em vista as características, elementos e análises empreendidas pela Geografia de acordo com as influências sofridas pelas matrizes teóricometodológicas, foi possível identificarmos o papel do elemento econômico na análise geográfica.

No âmbito da influência positivista, fica clara a preocupação e ênfase nos aspectos físicos ao procurar estudar as influências das condições naturais sobre as sociedades, chegando em alguns momentos a interpretações de caráter determinista. Neste caso, estando o foco central das análises voltado para as condições naturais e para a adaptação do indivíduo ao meio, o elemento econômico não comparece ou comparece apenas como parte descritiva na enumeração das características de um determinado território em termos produtivos, por exemplo.

Um tratamento diferenciado dado ao elemento econômico pode ser identificado nos trabalhos produzidos sob influência historicista. É principalmente a partir da perspectiva analítica fundada por Vidal de La Blache, na qual o homem é visto como um ser ativo que sofre a influência do meio, mas ao mesmo tempo atua sobre o mesmo transformando-o, que observamos como o econômico comparece como desdobramento do humano.

Nos trabalhos desenvolvidos dentro dessa perspectiva, as atividades econômicas como agricultura, comércio e circulação são vistas como fatores de desenvolvimento humano. No interior dos estudos regionais, há preocupação com a vida econômica da região a partir da discussão sobre fluxos, trabalho, produção, etc., articulando população, comércio, indústria, transportes, entre outros elementos do quadro regional.

Apesar da inserção do elemento econômico nas análises, este ocupava apenas uma parte do trabalho (a parte econômica) distinta e muitas vezes desarticulada do restante. A estrutura das monografias regionais francesas é bastante significativa para mostrar como isso ocorreu: havia a descrição geográfica (do quadro natural), e em seguida a caracterização da população e dos aspectos econômicos.

Esta estrutura serviu como modelo para grande parte dos trabalhos geográficos desenvolvidos no Brasil até os anos 1970. Nesses trabalhos, observa-se uma ênfase na descrição voltada ao estudo de produtos, tais como culturas agrícolas, pecuária, ou mesmo de fatos econômicos numa dada porção do território.

Em se tratando de uma análise geográfica, portanto, nos trabalhos de influência historicista deveria haver um exemplo localizado no território e, a partir de então, o econômico seria visto como uma parte dentro desse trabalho geográfico, na qual se discutiria sobre os aspectos que poderiam ser identificados com o econômico: a comercialização, a produção agrícola ou industrial e assim por diante. Nestes estudos, o geográfico e o econômico estavam nitidamente separados; a junção ocorreria com a distribuição geográfica do fato: a cultura da batata no estado de São Paulo, a bananicultura no litoral, a pecuária em Barretos, e assim por diante.

Já nos trabalhos influenciados pelo materialismo histórico e dialético, o econômico passa a ser visto como integrante da reflexão, como um elemento explicativo para analisar uma determinada questão e não apenas como um elemento em si. Isto se deve principalmente ao fato de que esta matriz teórico-metodológica destacava a importância da infra-estrutura, entendida como base econômica da sociedade para o entendimento desta.

Desta forma, o econômico deveria ser pensado como um elemento essencial do discurso, constituindose num componente interpretativo que permeava toda a análise geográfica. A produção material no âmbito da historicidade do espaço é ponto central para os trabalhos desenvolvidos sob a influência dessa matriz teóricometodológica. Os elementos econômicos, portanto, são destacados para o entendimento geográfico do espaço.

Pode-se concluir que, nos trabalhos desenvolvidos na Geografia a partir do referencial do materialismo histórico e dialético, há maior importância e tratamento diferenciado do econômico em relação àqueles influenciados pelo positivismo e historicismo.

\section{O ECONÔMICO NA GEOGRAFIA A PARTIR DAS TESES DA USP}

A reflexão desenvolvida anteriormente nos forneceu algumas "pistas" ou referenciais para a identificação e para a discussão sobre as influências do econômico no pensamento geográfico de forma geral. No entanto, a partir da análise das teses, ${ }^{4}$ identificamos e sistematizamos um conjunto mais específico de influências que compareceram como mais significativas

\footnotetext{
${ }^{4} \mathrm{O}$ conjunto de teses analisadas encontra-se relacionado ao final deste texto, junto às referências.
} 
NUNES, F. G. O econômico na geografia: uma reflexão a partir da produção...

e recorrentes. No quadro a seguir, sistema-tizamos tais influências.

A partir das teses analisadas, verificamos que os anos 1970 foram marcados pela discussão e pela crítica em relação a teorias e modelos provenientes principalmente da Economia neoclássica e sua aplicação na Geografia.

A influência dos referenciais da economia espacial de inspiração neoclássica na Geografia, com base nas teses analisadas, pode ser interpretada como um acontecimento de caráter positivo para uma renovação teórica e metodológica desta, mesmo que também represente um momento empobrecedor da análise geográfica.

É evidente que os modelos da economia espacial apresentaram limitações e sua utilização na Geografia trouxe resultados questionáveis sob vários pontos de vista. No entanto, é interessante notar que, a partir da crítica a esses referenciais, abriu-se caminho para a afirmação e para a importância do materialismo histórico na Geografia, notadamente com o trabalho de Oliveira (1978).

Se antes destes trabalhos críticos aos modelos da economia espacial tínhamos o econômico como parte do geográfico, a partir deles verifica-se a influência do econômico não só como objeto de crítica, mas principalmente como componente essencial da discussão, ou seja, como elemento constitutivo do referencial teórico e metodológico que passa a orientar a produção geográfica nos anos 1980 e 1990.

Nos anos 1980 e 1990, pode-se dizer que o econômico afirma-se na análise geográfica, ganhando destaque e importância nas discussões, principalmente por causa da incorporação do materialismo histórico e dialético como referencial teórico-metodológico na Geografia.

As influências sofridas por parte do pensamento econômico, então, apresentam alguns enfoques diferenciados, embora todos estejam relacionados aos referenciais teóricos e metodológicos do pensamento econômico marxista.

É notória a grande utilização de conceitos, idéias ou mesmo terminologias relativas ao pensamento econômico marxista nos trabalhos geográficos. Claro que esta utilização acaba sendo incorporada pela Geografia de forma mais ampla e torna-se parte do "vocabulário geográfico", mesmo atualmente. No entanto, queremos destacar que anteriormente, nos trabalhos da década de 1970, por exemplo, esse tipo de terminologia ou de utilização era praticamente inexistente, ou seja, não compunha a estrutura e redação dos trabalhos.

TIPO DE INFLUÊNCIA OU UTILIZAÇÃO DAS IDÉIAS PROVENIENTES DO PENSAMENTO ECONÔMICO PRESENTES NAS TESES ANALISADAS

\begin{tabular}{|c|c|c|}
\hline Tipo de influência ou utilizaçāo & Características & Períado de incidência \\
\hline Teoria da madernizaçāo da ag icultura & 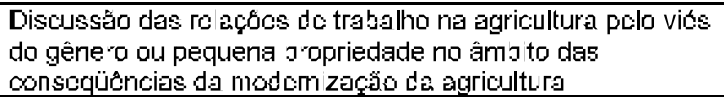 & Anos 1980 e 1990 \\
\hline Tcorias o idé as de lgnácio Rangel & $\begin{array}{l}\text { Aplicaçăo o tentetiva de comprovaçaso da validado costas } \\
\text { para a temática estudiada }\end{array}$ & Anos 1990 c 2000 \\
\hline $\begin{array}{c}\text { Teoria da renda ca terra (Marx e autores } \\
\text { da mesma I nha\} - rural }\end{array}$ & $\begin{array}{l}\text { A teoria é base para a reflexāo sobre a pequena produçäo e } \\
\text { sua condiç̧o de subondinaçăo no modo capitalista de } \\
\text { produria }\end{array}$ & Anos 1980 e 1990 \\
\hline $\begin{array}{c}\text { Teoria dè renda ca Lerra (Marrx a aulores } \\
\text { da mesma linha) - urbano }\end{array}$ & $\begin{array}{l}\text { A teoria é base para a reflexāo sobre a renda da tera } \\
\text { urbene e sua apropriaça no processo de produçăo } \\
\text { ierritorial e imobiliaria da cidade }\end{array}$ & Anos 1990 \\
\hline $\begin{array}{l}\text { Teorias proveniertes da economia } \\
\text { espacial \{Christäler e vonThünen\} }\end{array}$ & $\begin{array}{l}\text { Crítica às limitacöes explicativas apresentadas por estas } \\
\text { eorias }\end{array}$ & Аחos 1970 \\
\hline $\begin{array}{l}\text { leorias e inclielos proverientes dir } \\
\text { cconomia ospacial }\end{array}$ & 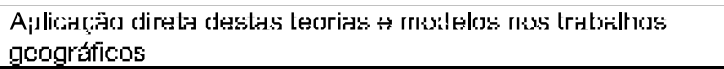 & Anibi 1990 \\
\hline $\begin{array}{l}\text { Conce tos c idéias proverientes do } \\
\text { [*risarnern.s marxisia }\end{array}$ & 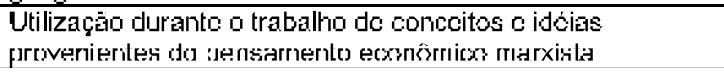 & 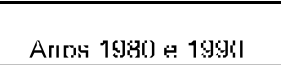 \\
\hline Desenvolvimento regional & $\begin{array}{l}\text { Aplicaçäo de modelos ana íticos para avaliaço do } \\
\text { dinamismo de ume rogiäo }\end{array}$ & Anos 1990 \\
\hline Reestruturaçāo industrial & $\begin{array}{l}\text { Discussão do novo paradiğma técoico-eco nômico o suas } \\
\text { repercussōes na ndústria }\end{array}$ & Апоs 1990 e 2000 \\
\hline $\begin{array}{l}\text { Constituiçāo de Quadros conjunturais ou } \\
\text { históricos da conomia nacional }\end{array}$ & $\begin{array}{l}\text { Utilizaçāo de dados, informacōes ou mesmo interpretacōes } \\
\text { acorca da conjurttra ou quostóos ospocfficas ca coonomia } \\
\text { nacional }\end{array}$ & Anos 1990 \\
\hline
\end{tabular}

FONIE: Levanta'ilente libliográlicol/20]14.

Org.: Flaviana G. Nunes. 
NUNES, F. G. O econômico na geografia: uma reflexão a partir da produção...

Neste sentido, expressões como "divisão social do trabalho", "exército industrial de reserva", "composição orgânica do capital", "acumulação de capital", "relações sociais de produção", "relações capital-trabalho", "mais-valia", entre outras, passam a ser cada vez mais comuns nos trabalhos geográficos, compondo de forma significativa os instrumentos explicativos das temáticas ou problemas abordados.

Além dessa influência mais disseminada e percebida no conjunto das teses, destaca-se também a influência, em particular, da teoria da renda da terra de Marx e de autores da mesma linha nos trabalhos analisados.

Marx elaborou um conjunto de reflexões em torno da questão da renda fundiária que serviram de inspiração ou pressuposto para alguns trabalhos desenvolvidos na Geografia, tanto no que diz respeito à renda da terra na cidade quanto no campo.

Neste sentido, há uma significativa valorização e afirmação do econômico como elemento explicativo dos processos que se desenvolvem no campo e na cidade, ou seja, a influência do pensamento econômico mostrase efetiva na medida em que os conceitos e categorias de cunho econômico são pedras fundamentais no desvendamento destas realidades por parte da Geografia.

Outro exemplo claro disso refere-se à grande influência exercida pelas formulações teóricas advindas da economia sobre a questão da modernização da agricultura. É significativo o número de trabalhos em que estas formulações são bases para explicar as relações de trabalho ou a pequena produção em diversas áreas do Brasil.

Durante toda a década de 1980 e até a primeira metade da década de 1990, as influências advindas do pensamento econômico de estrato marxista estiveram bastante presentes na produção geográfica. A partir da segunda metade dos anos 1990 ocorrem algumas mudanças, as quais trazem novas características e influências.

Uma influência direta da Economia Política brasileira pode ser identificada nas teses em que se constata a aplicação das idéias do corpo teórico das discussões de Ignácio Rangel. Nas teses analisadas percebemos que, independente da temática abordada, os autores não somente se apoiaram nas teorias desenvolvidas por Rangel, como também procuraram ao longo de suas análises comprovar as proposições teóricas dele a partir das especificidades dos casos estudados em sua articulação com o contexto da economia nacional.

A utilização e a tentativa de comprovação dos postulados de Rangel nos trabalhos geográficos mostram como houve uma influência direta da economia política brasileira, pelo menos no que diz respeito às contribuições deste autor nas análises geográficas.

$\mathrm{O}$ aspecto a ser destacado, neste caso, é que especificamente nas teses analisadas, o referencial teórico de Rangel é utilizado muito mais como uma proposta a ser aplicada do que como possibilidade de interpretação e entendimento da questão, fazendo com que, em alguns momentos, tenhamos a impressão de uma transposição dos elementos teóricos do autor para os casos estudados.

Nos anos 1990 e 2000 também verificamos a presença de análises sobre a indústria pautadas na questão da reestruturação industrial. Essas análises justificam-se a partir das mudanças ocorridas em escala mundial, caracterizadas principalmente pela emergência de um novo paradigma produtivo e tecnológico.

Neste sentido, destacam-se alguns referenciais teóricos do pensamento econômico utilizados nos trabalhos dos geógrafos, como por exemplo, a teoria da regulação, que foi desenvolvida por economistas franceses de inspiração marxista já no final dos anos 1970.

\section{O ECONÔMICO NA GEOGRAFIA: PERIODIZAÇÃO E PRINCIPAIS INFLUÊNCIAS}

Após as constatações e discussões realizadas sobre as principais influências do pensamento econômico percebidas na produção geográfica, procuramos refletir por uma perspectiva mais avaliativa sobre o(s) sentido(s) e significado(s) dessas influências para a Geografia.

Podemos dizer que até a metade da década de 1970 o econômico não se constituía como elemento componente das análises geográficas, estando sua função restrita a ser uma parte da análise, distinta e separada das demais. Além disso, o teor do econômico relacionava-se, em grande parte, a dados sobre produção, fluxos, mercadorias, atividades e assim por diante.

Nesta forma de abordagem, a conotação ao econômico recai sobre as atividades, produtos ou regiões, apresentando uma incapacidade para oferecer uma visão unitária, um panorama do conjunto do funcionamento da economia no espaço e da transcendência deste na organização do sistema econômico.

A economia aparece, portanto, como uma mera justaposição de setores de atividade encarregados de satisfazer as necessidades humanas, sobretudo as materiais. A sociedade, por sua vez, geralmente é 
NUNES, F. G. O econômico na geografia: uma reflexão a partir da produção...

relacionada à população em forma de volume, crescimento e distribuição, o que acarreta discussões com nenhum conteúdo político, nas quais não são mencionadas questões como trabalho e a dimensão social da produção. Neste sentido, as análises eram limitadas e pouco contextuais.

Uma influência mais clara e significativa do pensamento econômico na produção geográfica é identificada na segunda metade da década de 1970, com a introdução de referenciais e de metodologias da economia neoclássica. É interessante notar que, neste caso, a influência de tais referenciais propiciou também a introdução do pensamento econômico marxista utilizado como base para as críticas estabelecidas à influência da economia neoclássica na Geografia.

Consideramos a introdução do materialismo histórico a partir de teorias, conceitos, idéias e proposições metodológicas o principal caminho de afirmação do econômico na análise geográfica, ou seja, a partir da introdução desta base teórico-metodológica na Geografia, o econômico ganha importância, tendo papel central nas análises e se constituindo como elemento explicativo para determinadas questões.

A década de 1980 e os primeiros anos da década de 1990 foram marcados pela grande influência do materialismo histórico nos trabalhos geográficos. Pudemos verificar que, com base na teoria da modernização da agricultura e na teoria da renda da terra e suas influências nos estudos rurais e urbanos, bem como com a utilização de conceitos e idéias provenientes do pensamento econômico marxista, foram desenvolvidos muitos trabalhos.

Esses trabalhos tinham como prioridade a discussão do econômico como elemento essencial na explicação e na análise dos fatos geográficos. Desta forma, houve uma significativa valorização do econômico como elemento explicativo dos processos espaciais que se materializam em diversas realidades, advindo daí uma das principais críticas feitas aos trabalhos geográficos influenciados pelo materialismo histórico: o excesso de "economicismo" apresentado nessas análises, desconsiderando critérios e elementos não estritamente determinados pelas relações de produção como etnia, gênero, cultura e indivíduo.

Sánchez Hernández (2003, p. 108), analisando o que chama de um "decaimento" do impulso da economia política na Geografia Econômica, aponta esta questão afirmando que:

La lenta consolidación de los enfoques que insisten en la capacidad individual y social para efectuar elecciones según criterios no estrictamente determinados por las relaciones de producción: raza, género, cultura e individuo comienzan a cobrar importancia en la explicación de los procesos geoeconómicos en detrimento del sesgo estructuralista y economicista por el que comenzaba a deslizarse a la Geografía Económica. En este terreno, hay que resaltar la influencia de la teoría de la estructuración de Anthony Giddens, quien propone una interpretación de la sociedad donde los condicionantes estructurales no impieden que los individuos actúen com la libertad suficiente para elegir su destino particular y colectivo.

A partir da citação de Sánchez Hernández, entendemos que se consolidam enfoques que consideram a capacidade individual e social para efetuar escolhas segundo critérios como raça, gênero, cultura e indivíduo para a explicação dos processos geoeconômicos, os quais não são estritamente determinados pelas relações de produção. Neste sentido, o autor aponta uma tendência de relativização do econômico nas análises, conduzindo à introdução de outras dimensões das relações sociais que até então não eram consideradas e valorizadas.

Tais críticas e proposições só podem ser compreendidas a partir do contexto em que se inserem, o qual é caracterizado por processos de grande envergadura que afetam o funcionamento do sistema capitalista. No quadro desses processos, destacam-se a globalização e a emergência de um novo paradigma tecno-econômico de base informacional, além da própria simbologia da queda do Muro, a democratização e as tentativas de inserção na ordem econômica capitalista mundial das antigas nações sob influência da antiga URSS, paralelo ao caso brasileiro da consolidação da democracia e da busca de modernização das estruturas do Estado. Esses acontecimentos apresentam rebatimentos diretos no conjunto das ciências sociais, as quais passam a introduzir a discussão sobre a crítica pós-moderna na racionalidade científica, fato que afeta também a Geografia.

Neste contexto, tomando o caso específico dos trabalhos de Geografia Econômica, são incorporados os referenciais da teoria da regulação, por exemplo, que passam a influenciar as novas reflexões e abordagens, conforme verificamos nas análises sobre reestruturação industrial. Incorporam-se também novos paradigmas industriais a partir dos quais se passa a adotar outras idéias que consideram dimensões não estritamente econômicas, em detrimento de uma concepção mais vinculada aos referenciais marxistas.

Tendo em vista as principais características da teoria da regulação, principalmente o fato de partir do pressuposto de que a dinâmica capitalista não está limitada aos fatores econômicos, recaindo também na esfera social e política, podemos inferir que se aponta a 
NUNES, F. G. O econômico na geografia: uma reflexão a partir da produção...

possibilidade da Geografia analisar os fatos econômicos incorporando dimensões e explicações não estritamente econômicas.

\section{O ECONÔMICO NA GEOGRAFIA: CONSTRUINDO UM ESQUEMA INTERPRETATIVO}

Tendo em vista o conjunto de reflexões realizadas, procuramos estabelecer uma proposta interpretativa para discussão e entendimento do elemento econômico na Geografia.

Mesmo tendo por base apenas um segmento da produção geográfica nacional, (as teses de doutorado defendidas na FFLCH/USP entre 1970 e 2001), acreditamos que os parâmetros estabelecidos para a elaboração desta proposta interpretativa podem ser aplicados a outros segmentos da produção geográfica, visto que consideramos, além das temáticas e formas de influência do econômico nos trabalhos de Geografia, a relação destas influências com o contexto da Geografia nacional, bem como as matrizes teórico-metodológicas presentes e hegemônicas em cada momento.

Desta forma, se tomarmos a relação entre o elemento econômico e as matrizes teóricometodológicas constitutivas do pensamento geográfico, podemos dizer, e essa é nossa proposição central neste trabalho, que o principal caminho de afirmação do econômico na análise geográfica deve-se à introdução do materialismo histórico como referencial teóricometodológico.

Neste caso, devemos considerar não só as proposições metodológicas que conferiam ao econômico um papel central nas análises, mas também o conjunto de teorias, conceitos e idéias que foram utilizados pelos geógrafos em seus trabalhos.

\section{O econômico na Geografia: esquema interpretativo}

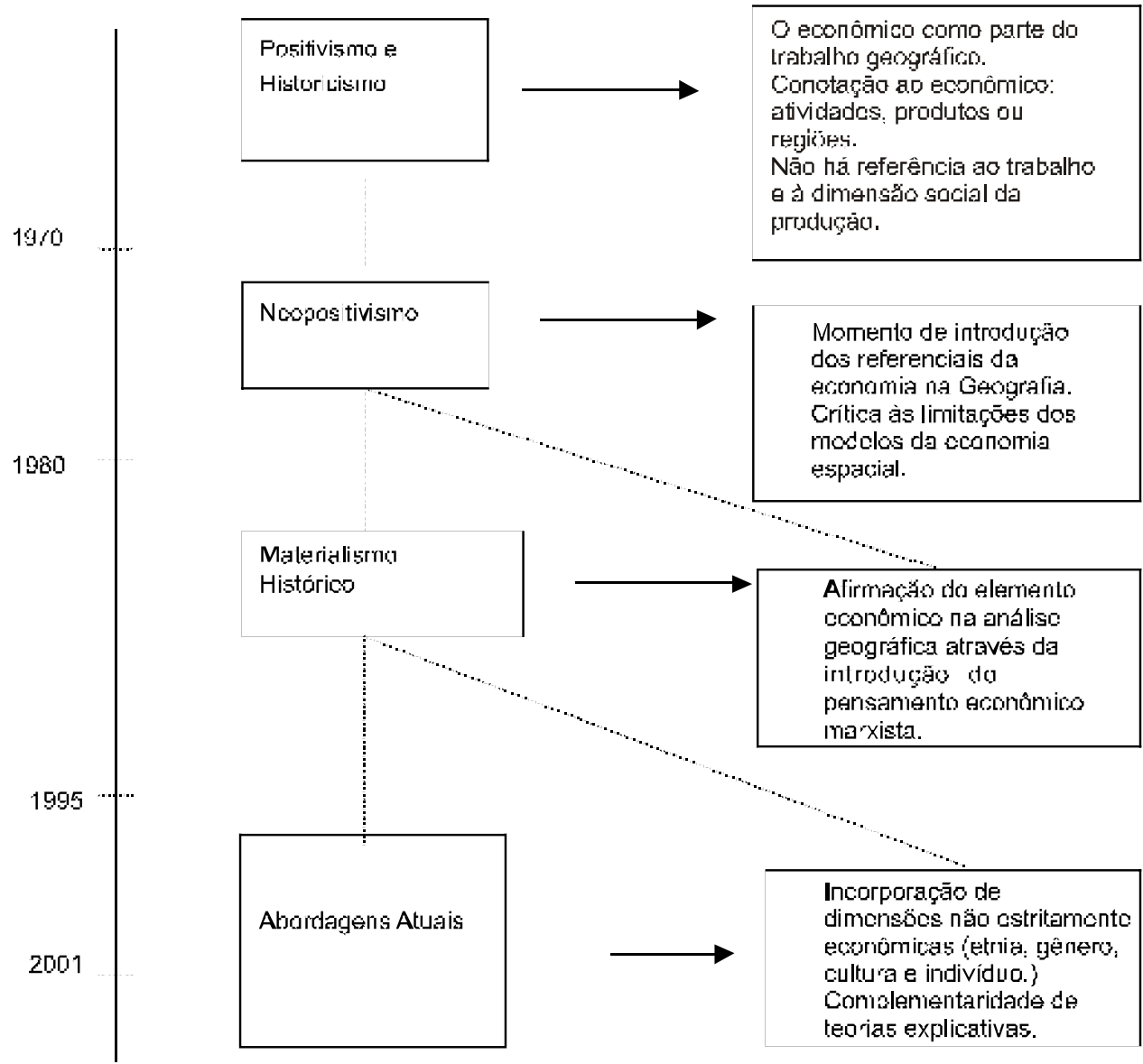

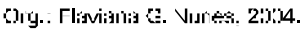


NUNES, F. G. O econômico na geografia: uma reflexão a partir da produção...

Consideramos, no entanto, como momento significativo para a construção dessa afirmação do econômico na análise geográfica a presença, utilização e crítica dos referenciais e metodologias da economia neoclássica. Isso porque, de fato, antes da introdução do materialismo histórico, a influência mais clara e significativa do pensamento econômico na produção geográfica pode ser verificada nos trabalhos produzidos sob a orientação da economia neoclássica.

Conforme já mencionado anteriormente, nos trabalhos produzidos no contexto do positivismo e do historicismo, o econômico não se constituía como elemento componente das análises geográficas, tendo a função restrita de ser uma parte distinta e sem articulação com o conjunto do trabalho.

O esquema anterior procurou ilustrar tal interpretação.

É importante destacar que os anos ou datas assinaladas no esquema não devem ser tomados como

\section{REFERÊNCIAS}

CAPEL, H. Filosofia y Ciencia en la Geografia contemporánea. Barcelona: Barcanova, 1981.

CARLOS, A. F. A. A Geografia brasileira, hoje: algumas reflexões. Terra Livre, São Paulo, n. 18, p. 161-168, 2002.

LÖWY, M. Ideologias e ciência social: elementos para uma análise marxista. 2. ed. São Paulo: Cortez, 1985.

\section{TESES DE DOUTORADO}

ABLAS, L. A de Q. Teoria do lugar central: bases e evidências empíricas - estudo de caso. São Paulo, 1978. Tese (Doutorado em Geografia Humana) - Faculdade de Filosofia, Letras e Ciências Humanas, Universidade de São Paulo.

ARANA, A. R. A. Os avicultores no Brasil: estratégias e adaptações - caso da Coperguaçu Descalvado-SP. São Paulo, 2001. Tese (Doutorado em Geografia Humana) Faculdade de Filosofia, Letras e Ciências Humanas, Universidade de São Paulo.

ARAÚJO, J. L. L. As transformações na produção artesanal de redes-de-dormir no nordeste brasileiro e suas relações com a produção do espaço. São Paulo, 1996. Tese (Doutorado em Geografia Humana) - Faculdade de Filosofia, Letras e Ciências Humanas, Universidade de São Paulo.

BARROS, N. C.C. Pequeno comércio no interior do nordeste do Brasil: estudo sobre o comércio ambulante na cidade de Campina Grande no Estado da Paraíba. São Paulo, 1987. Tese (Doutorado em Geografia Humana) - Faculdade de Filosofia, Letras e Ciências Humanas, Universidade de São Paulo. referências temporais absolutas. Sua delimitação tem o objetivo de representar ou demarcar a incidência ou maior representatividade de uma determinada abordagem e a conseqüente forma de influência do econômico na produção geográfica.

Além disso, as próprias matrizes teóricometodológicas identificadas devem ser entendidas no interior de um movimento mais amplo da ciência e não de forma linear. Apesar do surgimento de novas abordagens e referenciais teórico-metodológicos para a análise do econômico na Geografia, não significa dizer que não tenhamos ainda presentes influências do materialismo histórico e mesmo do positivismo e historicismo.

No caso do materialismo histórico, é evidente sua importância e presença até os dias atuais como referencial para a discussão e análise do econômico na Geografia, embora, como já destacado, coloque-se a necessidade da incorporação de dimensões não estritamente econômicas para a análise do econômico.

OLIVEIRA, A. U. de. A Geografia Agrária e as transformações territoriais recentes no campo brasileiro. In: CARLOS, Ana F. (Org.). Novos caminhos da Geografia. São Paulo: Contexto, 1999, p. 63-110.

SÁNCHEZ HERNÁNDEZ, J. L. Naturaleza, localización y sociedad: tres enfoques para la geografía económica. Salamanca: Ediciones Universidad de Salamanca, 2003.

BATISTA, L. C. Movimento da força de trabalho num contexto de integração acelerada no Mercosul. São Paulo, 2000. Tese (Doutorado em Geografia Humana) - Faculdade de Filosofia, Letras e Ciências Humanas, Universidade de São Paulo.

BENITES, M. G. Brasil central pecuário: interesses e conflitos. São Paulo, 1995. Tese (Doutorado em Geografia Humana) Faculdade de Filosofia, Letras e Ciências Humanas, Universidade de São Paulo.

CARVALHO, M. S. de. Pequena produção de café no Paraná. São Paulo, 1991. Tese (Doutorado em Geografia Humana) Faculdade de Filosofia, Letras e Ciências Humanas, Universidade de São Paulo.

DANTAS, J. Sertãozinho: uma sociedade dependente da agroindústria açucareira. São Paulo, 1972. Tese (Doutorado em Geografia Humana) - Faculdade de Filosofia, Letras e Ciências Humanas, Universidade de São Paulo.

DIGIACOMO, M. Estudo dos fluxos de transporte de cargas na área de influência de Campos Novos - SC. São Paulo, 1991. Tese (Doutorado em Geografia Humana) - Faculdade 
NUNES, F. G. O econômico na geografia: uma reflexão a partir da produção...

de Filosofia, Letras e Ciências Humanas, Universidade de São Paulo.

DINIZ FILHO, L. L. A dinâmica regional recente no Brasil: desconcentração seletiva com "internacionalização" da economia nacional. São Paulo, 2000. Tese (Doutorado em Geografia Humana) - Faculdade de Filosofia, Letras e Ciências Humanas da Universidade de São Paulo.

FIRKOWSKI, O. L. C. A nova territorialidade da indústria e o aglomerado metropolitano de Curitiba. São Paulo, 2001. Tese (Doutorado em Geografia Humana) - Faculdade de Filosofia, Letras e Ciências Humanas da Universidade de São Paulo.

GARRIDO FILHA, I. Garimpos de cassiterita - pesquisa geográfica. São Paulo, 1983. Tese (Doutorado em Geografia Humana) - Faculdade de Filosofia, Letras e Ciências Humanas da Universidade de São Paulo.

GOLDENSTEIN, L. Estudo de um centro industrial satélite: Cubatão. São Paulo, 1970. Tese (Doutorado em Geografia Humana) - Faculdade de Filosofia, Letras e Ciências Humanas da Universidade de São Paulo.

GRABÓIS, J. Os anéis da dependência: estudo geográfico da floricultura em Barbacena. São Paulo, 1978. Tese (Doutorado em Geografia Humana) - Faculdade de Filosofia, Letras e Ciências Humanas da Universidade de São Paulo.

JUNQUEIRA, C. B. A reapropriação do espaço a partir da integração agro-industrial. São Paulo, 1982. Tese (Doutorado em Geografia Humana) - Faculdade de Filosofia, Letras e Ciências Humanas, Universidade de São Paulo.

LAMOSO, L. P. A exploração de minério de ferro no Brasil e no Mato Grosso do Sul. São Paulo, 2001. Tese (Doutorado em Geografia Humana) - Faculdade de Filosofia, Letras e Ciências Humanas, Universidade de São Paulo.

LENCIONI, S. Reestruturação urbano-industrial: centralização do capital e desconcentração da metrópole de São Paulo-a indústria têxtil. São Paulo, 1991. Tese (Doutorado em Geografia Humana) - Faculdade de Filosofia, Letras e Ciências Humanas, Universidade de São Paulo.

LIMA, L. C. Novo espaço da produção: os tecnopólos. São Paulo, 1994. Tese (Doutorado em Geografia Humana) Faculdade de Filosofia, Letras e Ciências Humanas, Universidade de São Paulo.

MOTTA, N. C. Geografia da vida: (re)produção do espaço e relações sociais de trabalho do Espírito Santo. São Paulo, 1993. Tese (Doutorado em Geografia Humana) - Faculdade de Filosofia, Letras e Ciências Humanas, Universidade de São Paulo.

NOGUEIRA, E. A. Desenvolvimento regional, ocupação do espaço rural e o mercado de trabalho no sudoeste do estado de São Paulo. São Paulo, 1999. Tese (Doutorado em Geografia Humana) - Faculdade de Filosofia, Letras e Ciências Humanas, Universidade de São Paulo.

OLIVEIRA, A. U. de. Contribuição para o estudo da Geografia Agrária: crítica ao estado isolado de von Thünen. São Paulo,
1978. Tese (Doutorado em Geografia Humana) - Faculdade de Filosofia, Letras e Ciências Humanas, Universidade de São Paulo.

PINTAUDI, S. M. O templo da mercadoria: estudo sobre os shopping centers do Estado de São Paulo. São Paulo, 1989. Tese (Doutorado em Geografia Humana) - Faculdade de Filosofia, Letras e Ciências Humanas, Universidade de São Paulo.

PIRES, H. F. Reestruturação industrial e alta tecnologia no Brasil: as indústrias de informática em São Paulo. São Paulo, 1995. Tese (Doutorado em Geografia Humana) - Faculdade de Filosofia, Letras e Ciências Humanas, Universidade de São Paulo.

PIZZOLATTI, R. L. Os pequenos produtores do oeste catarinense: integrados ou entregados? São Paulo, 1996. Tese (Doutorado em Geografia Humana) - Faculdade de Filosofia, Letras e Ciências Humanas, Universidade de São Paulo.

SÁ, A. J. de. O espaço citricultor paulista nos anos 90: a (re)afirmação de um meio técnico-científico-informacional da globalização. São Paulo, 1998. Tese (Doutorado em Geografia Humana) - Faculdade de Filosofia, Letras e Ciências Humanas, Universidade de São Paulo.

SANTOS, R. C. B. dos. Rochdale e Alphaville: formas diferenciadas de apropriação e ocupação da terra na metrópole paulistana. São Paulo, 1994. Tese (Doutorado em Geografia Humana) - Faculdade de Filosofia, Letras e Ciências Humanas, Universidade de São Paulo.

SEABRA, M. F. G. As cooperativas mistas do estado de São Paulo: estudo de Geografia Econômica. São Paulo, 1973. Tese (Doutorado em Geografia Humana) - Faculdade de Filosofia, Letras e Ciências Humanas, Universidade de São Paulo.

SILVA, L. R. da. O espaço da pequena produção em Maraxamguape- RN. São Paulo, 1986. Tese-(Doutorado em Geografia Humana) - Faculdade de Filosofia, Letras e Ciências Humanas, Universidade de São Paulo.

SILVA, M. M. da. A linha de subordinação: trabalho da mulher e sobrevivência da pequena produção agrícola no agreste pernambucano. São Paulo, 1994. Tese (Doutorado em Geografia Humana) - Faculdade de Filosofia, Letras e Ciências Humanas, Universidade de São Paulo.

SPOSITO, E. S. Produção e apropriação da renda fundiária urbana em Pres. Prudente - SP. São Paulo, 1990. Tese (Doutorado em Geografia Humana) - Faculdade de Filosofia, Letras e Ciências Humanas, Universidade de São Paulo.

SPOSITO, M. E. B. O chão arranha o céu: a lógica da (re)produção monopolista da cidade. São Paulo, 1991. Tese (Doutorado em Geografia Humana) - Faculdade de Filosofia, Letras e Ciências Humanas, Universidade de São Paulo.

TEIXEIRA, M. A. As mudanças agrícolas no Mato Grosso do Sul: o exemplo da Grande Dourados. São Paulo, 1989. Tese (Doutorado em Geografia) - Faculdade de Filosofia, Letras e Ciências Humanas, Universidade de São Paulo. 
NUNES, F. G. O econômico na geografia: uma reflexão a partir da produção...

TSUKAMOTO, R. Y. Teiticultura no Brasil: subordinação e dependência. São Paulo, 1994. Tese (Doutorado em Geografia Humana) - Faculdade de Filosofia, Letras e Ciências Humanas, Universidade de São Paulo.

VICENTE, M. C. M. Inserção da força de trabalho feminina: as bóias-frias na agricultura do sudoeste paulista. São Paulo, 1997. Tese (Doutorado em Geografia Humana) - Faculdade de Filosofia, Letras e Ciências Humanas, Universidade de São Paulo.

VIEIRA, M. G. Processo de desenvolvimento econômico do centro-oeste paulista: a pequena e média empresa do setor metal-mecânico. São Paulo, 1994. Tese (Doutorado em Geografia Humana) - Faculdade de Filosofia, Letras e Ciências Humanas, Universidade de São Paulo. 